\title{
Management of dental pain in primary care
}

\section{SUMMARY}

Patients sometimes present to a medical practitioner with dental pain if they cannot see a dentist.

Doctors need to be aware of the common dental diseases that result in pain so they can help to manage the patient's symptoms until they are able to see a dentist.

Appropriate advice regarding analgesics for dental pain is important. Paracetamol and ibuprofen are more effective in combination than either of them alone, with or without opioids.

Antibiotics are only indicated as an adjunct to dental treatment when there are signs of systemic involvement, progressive and rapid spread of infection, or when the patient is immunocompromised.

\section{Introduction}

Patients may present to a medical practitioner with dental pain, dento-maxillofacial trauma and treatment-related complications. This happens frequently in emergency departments, but also in general practice. ${ }^{1}$ A recent survey found that dental conditions accounted for over 70,000 avoidable hospital admissions in Australia during 2016-17. ${ }^{2}$ Yet, many doctors have limited training in the diagnosis and management of common dental problems. ${ }^{3}$

Besides referral to a dentist, the medical practitioner can provide appropriate advice regarding analgesics, with consideration of the patient's medical history (including recent dental treatment), the benefits and risks of the drugs and severity of the pain. It is also important to know when antibiotics should and should not be prescribed. ${ }^{4}$ Community pharmacists also see many patients with dental pain, particularly out of hours, and need guidance about what to advise.

\section{Questions to ask when assessing oral pain}

When obtaining a pain history, the mnemonic SOCRATES can be useful: ${ }^{5}$

Site - Where is the pain?

Onset - When did it start?

Character - Can you describe the pain?

Radiation - Does the pain spread anywhere?

Associations - Are there other problems associated with the pain?

Time course - Does the pain follow any pattern? How long does it last?

Exacerbating or relieving factors - Does anything worsen or improve it?

Severity - How bad is the pain?

\section{Common types of dental pain}

Dental pain is usually acute, unilateral and localised within the mouth. ${ }^{6}$ It can be exacerbated by thermal or osmotic stimuli or when biting and can present with swelling. Figure 1 indicates where some of the more common conditions that cause dental pain can occur in a tooth. ${ }^{7}$

\section{Pain exacerbated by thermal or osmotic stimuli}

The management of dental pain that worsens with thermal or osmotic stimuli (e.g. sweets or acids) is outlined in Fig. 2. If the patient reports sensitivity or sharp, shooting pain to cold, hot or osmotic stimuli lasting only seconds to minutes, the painful tooth is likely to have an inflamed pulp. This should resolve and is called reversible pulpitis. If the inflammation progresses, the pulp may not be able to heal. This results in irreversible pulpitis. In this case, the patient may report dull or throbbing, poorly localised pain of longer duration. ${ }^{8}$

The term dentinal hypersensitivity is used interchangeably with reversible pulpitis as the patient presents with the same symptoms. However, dentinal

Occasionally, temporomandibular disorders can arise secondary to pulpitis. This can present as odontogenic and non-odontogenic pain simultaneously. ${ }^{9}$ There is a lack of evidence for the use of antibiotics to reduce pain associated with irreversible pulpitis and the patient should be advised to seek prompt dental treatment. ${ }^{10}$

\section{Pain when biting}

The management of dental pain from biting is outlined in Fig. 3. When assessing the patient, consider the character and location of the pain. Sharp pain with short duration may be localised to a vital tooth with cracks or dislodged dental restorations." hypersensitivity is related to exposed dentine.
Aovana Timmerman Specialist endodontist Peter Parashos Chair of Endodontics Head of Restorative Dentistry

Melbourne Dental School, University of Melbourne

\section{Keywords}

analgesia, root canal treatment, toothache

Aust Prescr 2020;43:39-44 https://doi.org/10.18773/ austprescr.2020.010

Related article: Managing acute dental pain without codeine. Aust Prescr 2020;43:64 


\section{Fig. 1 Diagram showing where common painful conditions occur in a molar tooth}

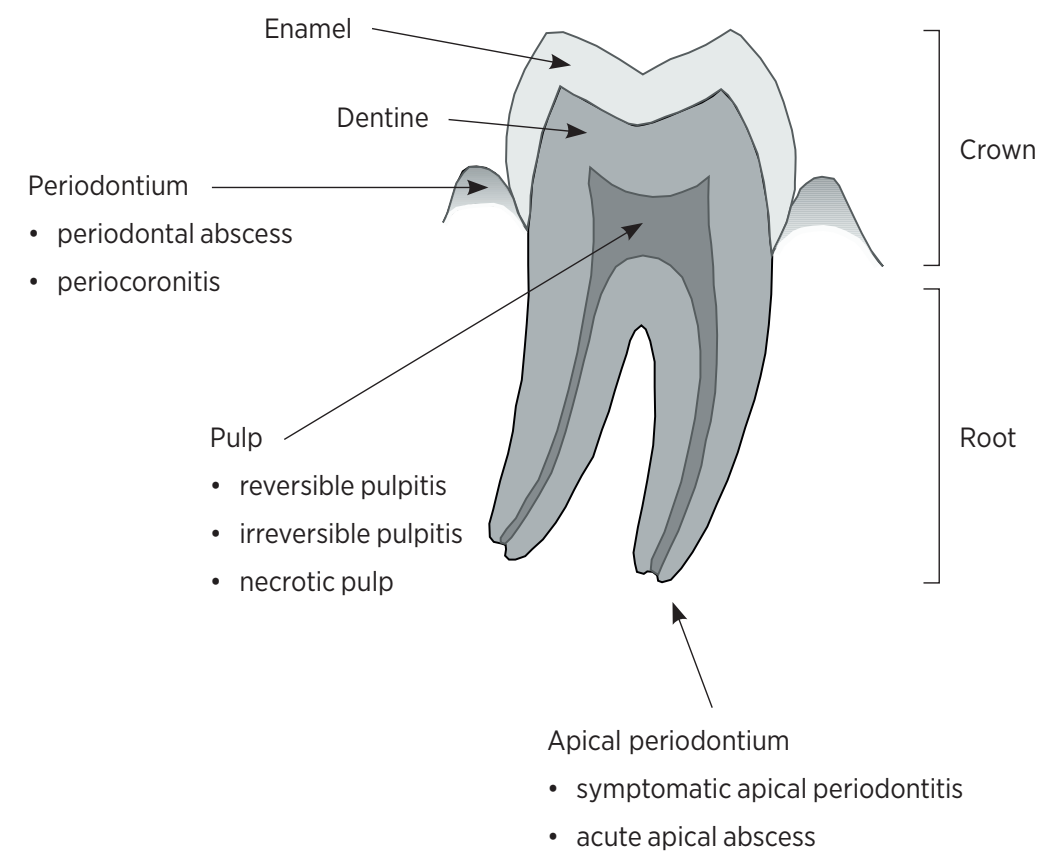

When pulp inflammation progresses to pulp necrosis, the symptoms associated with thermal or osmotic stimuli may resolve initially. Dull throbbing pain localised to a tooth with an infected root canal system can then occur when there is inflamed periodontium around the root apex (symptomatic apical peridontitis). Knowing the patient's history of symptoms and past dental treatment can be useful as pulp inflammation and necrosis usually develop from tooth decay. A patient with a history of root canal therapy can develop symptoms over time if the root canal system remains or becomes re-infected.

Other causes of dull throbbing pain include:

- food impaction - together with bacterial plaque this can result in gingival inflammation ${ }^{7}$

- $\quad$ bruxism (grinding of teeth)

- temporomandibular disorders

- oral ulceration

- periodontal issues with wisdom teeth (pericoronitis) - this may present with continuous pain localised near a wisdom tooth which is exacerbated by eating or brushing

- acute necrotising ulcerative gingivitis - this results from non-contagious infection of the gums and may present with painful bleeding, ulcerative gingival tissues and halitosis ${ }^{12}$
- dry socket (alveolar osteitis) - this may present with pain 1-4 days after tooth extraction so patients should be asked about recent dental treatment. The pain may radiate to the ear, eye or temporal region and be accompanied by halitosis or an unpleasant taste. ${ }^{6}$

When pain occurs with a temporal pattern (e.g. intermittent pain), it is likely to a have a nonodontogenic cause and the clinician should consider myalgia related to bruxism, cluster headaches or neuropathic pain. ${ }^{13}$ A patient with nocturnal bruxism may report discomfort, fatigue or pain in the jaw muscles and headache, especially in the morning. ${ }^{14}$

\section{Pain with swelling}

Urgent referral to a dentist is indicated when there is dental pain with swelling. A patient with an acute apical abscess will experience a rapid onset of spontaneous pain, which can sometimes be poorly localised and present with firm or fluctuating swelling in the overlying soft tissues. The tooth is extremely tender when palpated or tapped. ${ }^{15}$

The symptoms and clinical presentation of a periodontal abscess can be confused with an acute apical abscess. However, pain from a periodontal abscess is usually localised. From the history, the patient may have had previous periodontal treatment, a history of periodontal abscess or a recent soft tissue trauma sustained during eating. On examination, there may be an ovoid swelling in the gingival tissues along the lateral surface of the root. ${ }^{16}$ Suppuration can present spontaneously or when the abscess is pressed. ${ }^{16}$ Again, systemic antibiotics are only indicated as an adjunctive treatment when there is systemic involvement or spread of infection, or if adequate drainage cannot be provided. ${ }^{16}$

\section{Maxillary sinusitis}

The symptoms associated with maxillary sinusitis can mimic pain of pulpal origin and vice versa. ${ }^{17}$ The medical history of a patient with sinusitis may reveal recent upper respiratory tract infection, a history of chronic rhinitis or pain associated with air travel. ${ }^{18}$ Symptoms can be unilateral or bilateral and are described as a continuous dull pain exacerbated by biting, touch, postural changes or exercise..$^{19}$ The patient may also have nasal congestion and discharge, headache, facial pain or fullness, erythema over the cheeks and olfactory disturbance. ${ }^{19}$

Maxillary sinusitis may be suspected to have an odontogenic cause when it does not respond to medical therapy and presents with unilateral symptoms and a history of dental or jaw pain. The patient may have a history of dental caries, periodontal disease or complications with surgery 


\section{Fig.2 Management of dental pain exacerbated by thermal or osmotic stimuli}

Pain exacerbated by thermal or osmotic stimuli

Tooth with previous root canal therapy

Refer to a dentist as symptoms are likely to be arising from a neighbouring tooth with vital tissues.

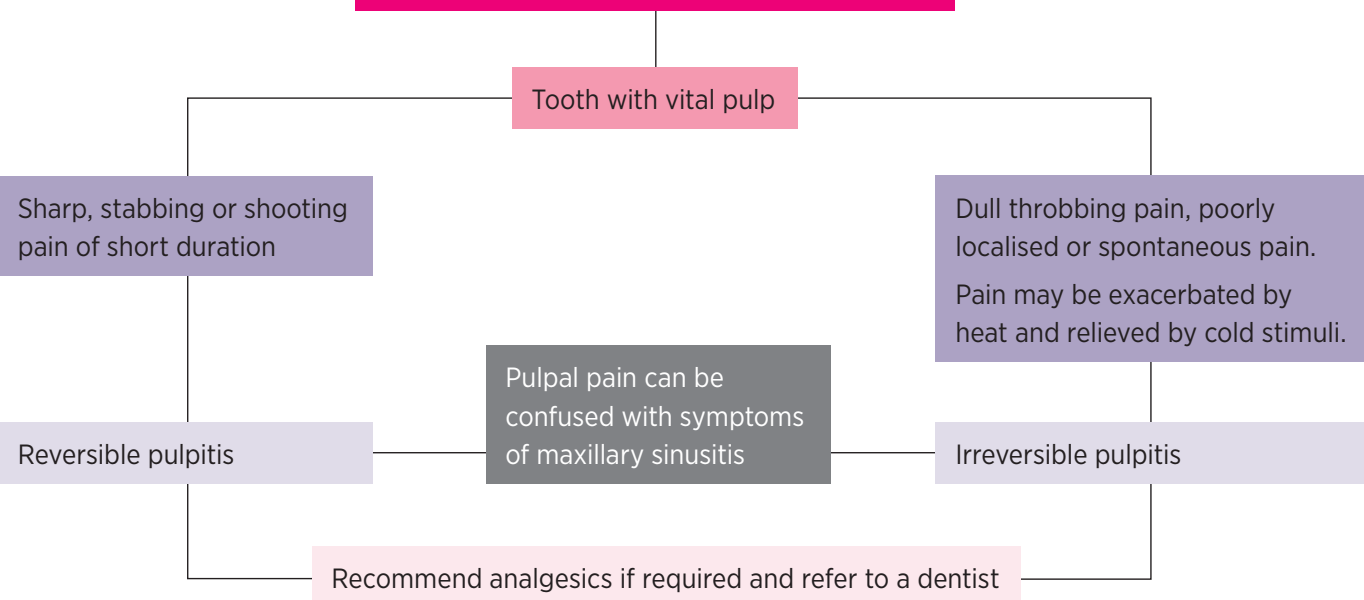

\section{Fig. 3 Management of dental pain on biting}

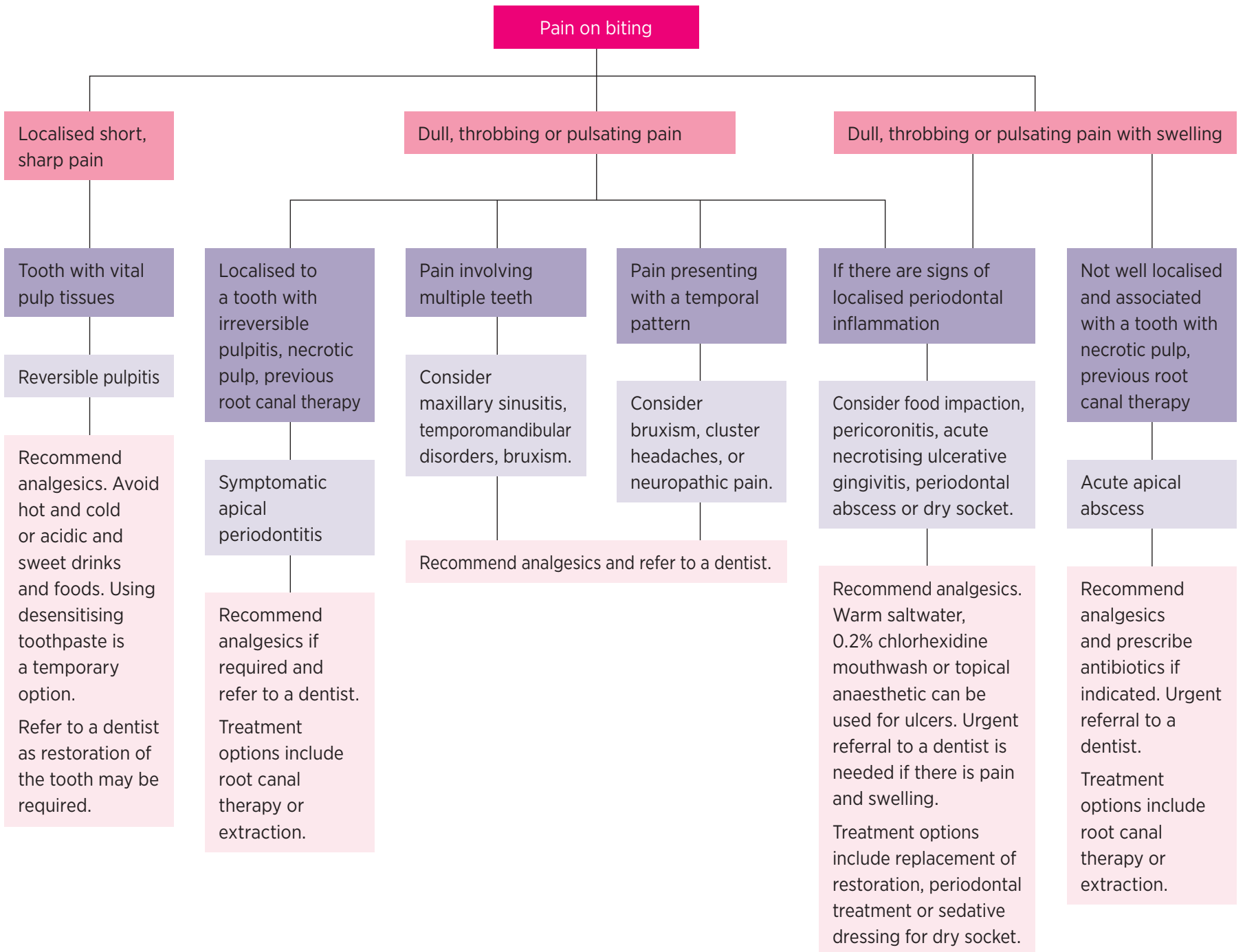


in the posterior maxilla. ${ }^{20}$ If sinusitis of odontogenic cause is suspected, the patient should be directed to a dentist.

\section{Orofacial pain of non-odontogenic origin}

Warning signs that can alert the clinician to pain of non-odontogenic origin are listed in the Box.21-24 Knowing the location and timing of the pain can help to differentiate between musculoskeletal, neuropathic, vascular, primary headache or mixed conditions. ${ }^{6}$

Chronic orofacial pain has a non-odontogenic origin and is characterised by painful regional syndromes with a chronic unremitting pattern. ${ }^{25}$ The most common example is temporomandibular disorders which can present as unilateral or bilateral, continuous or episodic pain. ${ }^{21}$ The patient may complain of pain in the jaw, temple, inside or in front of the ear, which is modified by jaw movements. ${ }^{22}$ Fibromyalgia, back pain, chronic fatigue syndrome, depression and headache can be associated with a temporomandibular disorder. ${ }^{23}$ Clicking, crepitus, pain, trismus or locking of the temporomandibular joints can present with disruption of the disc movement. ${ }^{21}$ Jaw claudication can potentially be a sign of temporal arteritis and the patient can be referred to an oral maxillofacial surgeon for diagnosis and management.

\section{Analgesia}

As non-steroidal anti-inflammatory drugs (NSAIDs) produce analgesic and anti-inflammatory actions by inhibiting cyclooxygenase enzymes, they are the drug of choice for dental pain. Their efficacy has been well supported by systematic reviews. ${ }^{26}$ Taking ibuprofen

\section{Box Some features of non-odontogenic dental pain}

- Bilateral pain or multiple teeth with pain

- Pain that does not follow a neurological distribution

- Pain described with unusual characteristics such as burning, stinging, electric, shooting, pins and needles

- Pain that is chronic and unresponsive to dental treatment

- Pain not consistently relieved by local anaesthesia

- Pain concurrent with a headache

- Pain triggered or exacerbated by palpation of trigger points or muscles of the head and neck

- Pain associated with clicking or locking of the temporomandibular joints

- Pain triggered by emotional stress, physical exercise or head position

- Pain accompanied by psychiatric features such as hallucination or delusions

- Pain associated with abnormal involuntary movements

Source: references $21-24$ and paracetamol together has been recommended because the combination is more effective than either drug alone. ${ }^{27}$ If NSAIDs are contraindicated, paracetamol or the combination of paracetamol and oxycodone can be recommended. As opioids result in less analgesia and more adverse effects, ${ }^{27}$ they are only prescribed, as an adjunct to ibuprofen or paracetamol, at the lowest possible dose and shortest duration.

Administration of a dental block may be effective for initial management of severe pain before followup with oral analgesics, especially in an emergency department.

Topical local anaesthetics (e.g. 2\% lignocaine gel) are effective for temporary pain relief in patients presenting with oral ulceration or painful oral mucosal conditions. However, the patient should be warned about the risk of further trauma when the oral mucosa is numb. ${ }^{28}$

\section{Indications for antibiotic therapy}

Antibiotics are only indicated as an adjunct to definitive treatment when there are systemic signs of infection (fever, malaise, lymphadenopathy, trismus), progressive and rapid spread of infection (cellulitis or Ludwig's angina) or when the patient is immunocompromised. ${ }^{29}$ Antibiotics for odontogenic infections include:

- phenoxymethylpenicillin or amoxicillin

- amoxicillin with metronidazole

- amoxicillin with clavulanate or clindamycin. ${ }^{29}$

If the patient presents with spreading dental infection, systemic sepsis or the risk of airway compromise, they will need immediate referral to the emergency department.

Currently, prophylactic antibiotics are only indicated before dental procedures associated with a high risk of bacteraemia such as surgical procedures including extraction for patients with specific conditions such as prosthetic heart valves, previous infective endocarditis, some congenital heart defects, cardiac transplants with subsequent valvopathy and rheumatic fever with high risk of endocarditis. ${ }^{30}$

\section{Conclusion}

Management of dental pain in a medical setting follows specific guidelines for either definitive treatment or to provide relief before referral for dental treatment. Antibiotics are rarely indicated for management of odontogenic infections and are used as adjuncts to dental treatment. $<$ 


\section{Glossary of dental terms}

- Acute apical abscess - an inflammatory reaction to pulpal infection and necrosis characterised by rapid onset, spontaneous pain, tenderness of the tooth to pressure, pus formation and swelling of associated tissues.

- Acute necrotising ulcerative gingivitis - an inflammatory disease of the gingiva indicating an impaired host response. Signs and symptoms include pain, interdental papillary necrosis, presence of a pseudomembrane and a tendency towards spontaneous bleeding.

- Alveolar osteitis - localised inflammation of bone in the alveolus following tooth extraction. Also known as dry socket.

- Bruxism - involuntary, habitual grinding of teeth, typically during sleep.

- Irreversible pulpitis - a clinical diagnosis based on subjective and objective findings indicating that the inflamed dental pulp is unable to heal.

- Pericoronitis - acute inflammation of the gingiva or mucosa surrounding a partially erupted tooth, especially wisdom teeth.
- Periodontium - the tissues that support the teeth including the gingiva, alveolar mucosa, cementum, periodontal ligament and supporting alveolar bone.

- Pulp - a richly vascularised and innervated connective tissue of mesenchymal origin in the central space (root canal system) of a tooth.

- Reversible pulpitis - a clinical diagnosis based on subjective and objective findings indicating that inflammation should resolve, and the pulp will return to normal.

- Symptomatic apical periodontitis inflammation and destruction of the apical periodontium causing pain on biting or when touched or tapped.

- Temporomandibular disorders - a group of disorders involving the masticatory muscles, the temporomandibular joint and associated structures. It can be divided into four main categories of myalgia, arthralgia, intra-articular disorders and headaches.

\section{REFERENCES}

1. Skapetis T, Gerzina T, Hu W. Management of dental emergencies by medical practitioners: recommendations for Australian education and training. Emerg Med Australas 2011;23:142-52. https://doi.org/10.1111/j.1742-6723.2011.01384.x

2. Australian Institute of Health and Welfare. Oral health and dental care in Australia. Canberra: Australian Government; 2019. https://www.aihw.gov.au/reports/dental-oralhealth/oral-health-and-dental-care-in-australia/contents/ hospitalisations [cited 2020 Mar 1]

3. Samaei H, Weiland TJ, Dilley S, Jelinek GA. Knowledge and confidence of a convenience sample of Australasian emergency doctors in managing dental emergencies: results of a survey. Emerg Med Int 2015;2015:148384. https://doi.org/ 10.1155/2015/148384

4. Antibiotic prophylaxis for dental procedures. In: Oral and dental. Version 3. Melbourne: Therapeutic Guidelines Limited; 2019. pp. 189.

5. Scully C. Aide memoires in oral diagnosis: mnemonics and acronyms (the Scully system). J Investig Clin Dent 2012;3:262-3. https://doi.org/10.1111/jicd.12005

6. Zakrzewska JM. Differential diagnosis of facial pain and guidelines for management. Br J Anaesth 2013;111:95-104. https://doi.org/10.1093/bja/aet125

7. Wetherell J, Richards L, Sambrook P, Townsend G. Management of acute dental pain: a practical approach for primary health care providers. Aust Prescr 2001;24:144-8. https://doi.org/10.18773/austprescr.2001.155

8. Friend LA, Glenwright HD. An experimental investigation into the localization of pain from the dental pulp. Oral Surg Oral Med Oral Pathol 1968;25:765-74. https://doi.org/10.1016/0030-4220(68)90046-7

9. Wright E. Pulpagia contributing to temporomandibular disorder-like pain: a literature review and case report. J Am Dent Assoc 2008;139:436-40. https://doi.org/10.14219/ jada.archive.2008.0186

10. Agnihotry A, Fedorowicz Z, van Zuuren EJ, Farman AG, Al-Langawi JH. Antibiotic use for irreversible pulpitis. Cochrane Database Syst Rev 2016:CD004969. https://doi.org/10.1002/14651858.CD004969.pub4
11. Kahler W. The cracked tooth conundrum: terminology, classification, diagnosis, and management. Am J Dent 2008;21:275-82.

12. Murayama $Y$, Kurihara $H$, Nagai A, Dompkowski D, Van Dyke TE. Acute necrotizing ulcerative gingivitis: risk factors involving host defense mechanisms. Periodontol 2000 1994;6:116-24. https://doi.org/10.1111/j.1600-0757.1994.tb00031.x

13. Moule AJ, Lamar Hicks $M$. What is the patient telling you? In: Diagnosing dental and orofacial pain: a clinical manual. Oxford, UK: Wiley Blackwell; 2016. pp. 3-18.

14. American Academy of Sleep Medicine. International classification of sleep disorders. 3rd ed. Westchester (IL): AASM; 2014

15. Glickman GN, Schweitzer JL. Endodontic diagnosis. Endodontics Colleagues for Excellence Fall 2013. https://www.aae.org/specialty/publications-research/ endodontics-colleagues-excellence [cited 2020 Mar 1]

16. Newman MG, Takei HH, Klokkevold PR, Carranza FA. Carranza's clinical periodontology. 12th ed. St Louis (MO): Elsevier Saunders; 2015. pp.465-9.

17. Schwartz S, Cohen S. The difficult differential diagnosis. Dent Clin North Am 1992;36:279-92.

18. Hauman $\mathrm{CH}$, Chandler NP, Tong DC. Endodontic implications of the maxillary sinus: a review. Int Endod J 2002;35:127-41. https://doi.org/10.1046/j.0143-2885.2001.00524.x

19. Hegarty AM, Zakrzewska JM. Differential diagnosis for orofacial pain, including sinusitis, TMD, trigeminal neuralgia. Dent Update 2011:38:396-408. https://doi.org/10.12968/ denu.2011.38.6.396

20. Patel NA, Ferguson BJ. Odontogenic sinusitis: an ancient but under-appreciated cause of maxillary sinusitis. Curr Opin Otolaryngol Head Neck Surg 2012;20:24-8. https://doi.org/10.1097/M00.0b013e32834e62ed

21. Zakrzewska JM. Multi-dimensionality of chronic pain of the oral cavity and face. J Headache Pain 2013;14:37. https://doi.org/10.1186/1129-2377-14-37

22. Keiser K, Hargreaves $K$. Building effective strategies for the management of endodontic pain. Endod Topics 2002;3:93-105 https://doi.org/10.1034/j.1601-1546.2002.30109.x 
23. Dworkin SF, Burgess JA. Orofacial pain of psychogenic origin: current concepts and classification. J Am Dent Assoc 1987;115:565-71. https://doi.org/10.1016/S0002-8177(87)54009-0

24. Linn J, Trantor I, Teo N, Thanigaivel R, Goss AN. The differential diagnosis of toothache from other orofacial pains in clinical practice. Aust Dent J 2007;52(Suppl):S100-4. https://doi.org/10.1111/j.1834-7819.2007.tb00518.x

25. Benoliel R, Sharav Y. Chronic orofacial pain. Curr Pain Headache Rep 2010;14:33-40. https://doi.org/ 10.1007/s11916-009-0085-y

26. Smith EA, Marshall JG, Selph SS, Barker DR, Sedgley CM. Non-steroidal anti-inflammatory drugs for managing postoperative endodontic pain in patients who present with preoperative pain: a systematic review and metaanalysis. J Endod 2017;43:7-15. https://doi.org/10.1016/ j.joen.2016.09.010
27. Moore PA, Ziegler KM, Lipman RD, Aminoshariae A Carrasco-Labra A, Mariotti A. Benefits and harms associated with analgesic medications used in the management of acute dental pain: An overview of systematic reviews. J Am Dent Assoc 2018;149:256-265.e3. https://doi.org/ 10.1016/j.adaj.2018.02.012

28. Talacko AA, Gordon AK, Aldred MJ. The patient with recurrent oral ulceration. Aust Dent J 2010;55 Suppl 1:14-22 https://doi.org/10.1111/j.1834-7819.2010.01195.x

29. Segura-Egea JJ, Gould K, Sen BH, Jonasson P, Cotti E, Mazzoni A, et al. European Society of Endodontology position statement: the use of antibiotics in endodontics. Int Endod J 2018;51:20-5. https://doi.org/10.1111/iej.12781

30. Daly CG. Antibiotic prophylaxis for dental procedures. Aust Prescr 2017;40:184-8. https://doi.org/10.18773/ austprescr.2017.054 